\title{
Improving Educational Leadership of Chilean School Principals: A Research Proposal to Develop Instructional Leadership Capacity
}

\author{
Felipe Sepúlveda \\ Universidad Católica de la Santísima Concepción, Chile
}

\begin{abstract}
During the last decade in Chile, a strong social movement that calls for improving accessibility and quality of public funded education has resulted on developing reforms aimed to change the system paradigms. The current administration is committed to develop transformational reforms directed to improve schools facilities, acquiring new educational materials and improving the working conditions and professional development opportunities for teachers. School principals capable to lead the process become a relevant piece to carry out the new educational reform. This research uses the instructional leadership framework to gather information about Chilean school principals' leadership skills. It is proposed to use the Principal Instructional Management Rating Scale (PIMRS) to assess the principals' perceptions and how teachers perceive the school leaders' instructional leadership behavior. The gathered data will be helpful to identify the strengths and weakness of Chilean school leaders and to develop conceptual models to better understand the causal relationships between the principal leadership, the school contexts and the students' academic achievement.
\end{abstract}

\section{Introduction}

During the last decade in Chile, probably due to a more developed society, were the primary needs were already met, a strong movement toward improving the quality and accessibility to public funded schools impacted the current educational reforms. Chile was accepted in The Organization for Economic Co-operation and Development (OECD) in 2009. From this moment the country started to be compared with the strongest economies in the world. Compared with other countries from the OECD, Chile has work to be done in raising the quality of education measured by international standardized assessments (i.e. PISA test) and also to improve the country investment on public education. The new administration that won presidential elections in 2014 is committed to develop foundational transformations to the educational system in order to improve financial support and raise the quality of public educational system.

The current and future educational reforms taking place in Chile are directed toward a modernization of an outdated educational structure. A high effort is taking place toward designing a stronger and equalitarian public educational system that provides better opportunities for each citizen based on their academic foundations. Chile expects to become a developed country in the next 10 years, and setting out strong foundations on education is an imperative step toward meeting this goal.

\section{Educational Leadership in Chile}

The current educational reform in Chile is directed to change the system paradigms about the accessibility, diversity and funding to public schools. It is expected that schools will receive a higher amount of funds, which should be used primarily to improve the quality of education by updating the schools facilities, acquiring new educational materials and improving working conditions and professional development opportunities for teachers. Raising the amount of resources available for developing and implementing better educational programs is a big step for modernizing the Chilean public education, but having well prepared schools administrators able to lead the process, is a key piece for successfully developing and implementing an improvement plan on every public school.

The new educational reforms involve schools able to adapt for new changes at all levels of school administration. Most of the requirements come from new regulations promoted by the Chilean central government. Schools will be required to develop new skills and implement new instructional methodologies to be able to meet the new demands mandated by the Chilean Ministry of Education. Therefore leading a school improvement initiative is a challenging process and requires considering external factors (i.e. new educational policies, school community) and internal factors (i.e. teachers motivation, school infrastructure, fidelity on implementing the school instructional plan). This is not a simple task and requires a school leader capable to understand the change process in 
organizations, create the conditions for collaborative work, promote opportunities to reflect on current practice and facilitate school liaison with the surrounding community.

Compared with neighbor countries, the Chilean school principal figure is a well defined job position were more than $90 \%$ of school principals have a full time jobs [1]. However, how principals use to administer their time is not very positive indicator compared with other Latin American countries. The Chilean principals expend more time on administrative duties ( $31.3 \%$ of their time), leaving only a third of their time (31.1\%) allocated for instructional duties like monitoring, assessments, teacher orientation, and curriculum implementation [1]. It is evident that schools principals should be more focused on duties directed to improve the students' academic achievement like: monitoring academic practice at school, providing meaningful feedback, working collaboratively with teachers, and analyzing students' academic achievement data.

Lately some progress was made as an effort to provide greater amount school governance to principals by passing the Law for Quality and Equity on Education (Ley de Calidad y Equidad de la Educación, $\left.\mathrm{N}^{\mathrm{o}} 21.501,2011\right)$. This legislation piece provides some control to school administrators to manage the school staff, allowing principals to layoff up to $5 \%$ of the school teachers with basic and unsatisfactory teaching performance, and assign teaching incentives or salary increases based on professional performance. Furthermore, the Chilean Ministry of Education have promoted opportunities of professional development for principals by organizing workshops together with local universities, and providing scholarships to pursue graduate studies in the area of educational administration and leadership. All these initiatives allow principals to update their knowledge on current effective educational practice associated with instructional leadership research. Besides the relevant initiatives associated with principalship and professional development supported by the Chilean government, still there is a need to gather more information about their leadership characteristics and how they use it to carry out a school improvement process.

\section{Influence of the School Principal on Developing the School Improvement Plan}

Researchers agree that school leadership is a relevant factor that contributes to improve students' educational outcomes. School leaders need to be capable to define the school's mission and develop reliable goals that move the school toward continuous academic improvements. However, great principals do not get good results by themselves. They need to be capable to inspire by effectively motivating the school staff and provide instructional support for teachers. Effective school leaders develop cohesion around their team helping to bind people and their values to the work they do in the process of improving schools and working with one another [3]. A widespread research meta-analysis inform that improving the principals leadership skills can have profound effects on the achievements of students in their schools [4]. Where the principal capacity of flexibility, situational awareness, monitoring/evaluating and maintain a school structure that protect instructional time, presented the higher correlations with students' academic performance. Another research that examined the impact of different styles of leadership on student academic and nonacademic outcomes, found that the stronger effects of school leadership were associated with promoting teaching learning and development [5].

Therefore, considering a school a complex system, developing effective school leadership is a fundamental piece to bring academic improvement demonstrated by the students' academic performance. Teachers are recognized as the most relevant factor that impacts the students' academic achievement, but the school principal should be focused on generating the best conditions for learning by developing a school culture that promotes teacher collaboration, high academic expectations and organizational learning. Therefore, school leaders are responsible for creating the appropriate conditions for good teachers to thrive and perform at high levels which finally should be reflected on improving academic achievement of students

The Chilean regulation on education requires each accredited school to develop an Institutional Educational Plan (Proyecto Educativo Institucional, PEI) that establish the school vision, mission and values. The PEI should specify the main objectives around shared goals with the school community and define the pedagogical model used to implement the curriculum of different content areas. Also, public schools with a high population of students classified as vulnerable based on their socioeconomic condition can receive an extra amount of money to support instruction, purchase pedagogical materials and provide staff development to teachers. Public schools that classify to receive an additional budget from the government are required to develop a school improvement plan (Proyecto de Mejoramiento Educativo, PME). The school PME should reflect short-term goals (one year) and mid-term goals (4 years) created through a process that includes a diagnostic, planning, implementation and evaluation. However, the sole requirement of the development of an institutional educational plan, a school improvement plan and receiving supplemental funds does not guarantee significant improvements of the 
quality of public education. It is required a well prepared school leader able to put together an instructional plan to comply with the government requirements but also to create opportunities reflection toward developing an organization that learn from previous experiences. In general effective leaders are low on compliance for the sake of compliance, and high on influence for the sake of learning. They influence others to learn and to take related action. The development of a school PEI and PME should be based on a collaborative effort dependent on a culture and climate that support growth and learning for teachers and the organization. Considering the formal requirement of generating and implementing a school PEI and PME prescribed by the current Chilean legislation, school principals' have the opportunity to use them as a management tool focused on school improvement based on local needs and the necessities identified by the school professional learning community.

\section{Educational leadership styles}

The current literature in the field of education usually refers to three mayor leadership styles associated with successful school academic improvement: instructional leadership, transformational leadership and ultimately distributed leadership. In general, school leaders that show attributes associated with one or more leadership styles described above are capable to develop a right balance between improving the students' academic performance, and involving the school staff around a common vision and work collaboratively.

\subsection{Instructional Leadership}

The concept of instructional leadership was first used in the mid-eighties to characterize principals who used their authority and position of power together with their knowledge and experience to achieve sustained impacts on faculty motivation and student learning [6]. The main role of an instructional leader is to develop the school strategies directed to improve the students academic achievement. Principals who recognize themselves around the idea of instructional leadership generally show good results in areas with high poverty rates [7]. This leadership style is especially effective on setting clear expectations focused towards improving the students academic performance and establishing a positive school climate for learning. The emphasis of instructional leadership has been widely and sustainably used in a variety of educational systems, showing that it is an effective way to lead school located within different contexts. A proposed instructional leadership framework describes three dimensions which include: defining the school mission, managing the instructional program and developing the school learning climate program [8]. This framework has been maintained for over 30 years with small variations focused on a better description of the school principal role on each dimension.

The great interest on studying the impacts of this leadership approach produced abundant qualitative and quantitative data directed to evaluate how this leadership focus can impact the school academic improvement. Research data consistently shows that school principals with demonstrated skills in each of the dimensions described for instructional leadership are capable to successfully direct school changes towards the school effectiveness improvement [9]. The concept of instructional leadership is not new in the field of education, but this approach is been maintained over the time demonstrating consistency and efficacy on the implementation of educational improvement plans.

\subsection{Transformational Leadership}

This leadership approach is centered on enhancing the capabilities of the school staff, increasing their motivation at all levels in the organization and developing high levels of commitment toward achieving ambitious goals. The transformational leadership approach tries to develop an appropriate balance between transactional and transformational activities. The transactional duties are important for sustaining the organization structure and include developing organizational procedures and routines and administrative responsibilities. However transformational leaders are focused on developing and communicating a shared school vision and goals, providing intellectual stimulation, modeling best professional practices and values, and providing individualized support to the school staff. School leaders with a transformative style comply with the rules and procedures prescribed by bureaucratic structures, but besides that, they find appropriate ways to motivate and engage people, unlike transactional leaders do [10].

The transformational leadership approach uses moral foundations based on four main components: idealized influence, inspirational motivation, intellectual stimulation, and individualized consideration [11]. Managers who focus their action based on a transformational style have the ability to effectively communicate the organization's vision by establishing a meaningful purpose around the school's educational project. The development of a common organizational vision, builds capacity to work collaboratively and overcome major challenges to achieve ambitious goals [12]. Therefore, transformational leadership has a direct impact on the school culture and teachers motivation. Currently, this leadership approach is widespread 
around the educational field and it is seen as an effective alternative to meet the needs of complex and diverse systems that generally characterize the public school environment.

\subsection{Distributed Leadership}

The distributed leadership style is described as a particularly suitable approach to be applied on the complex educational world, because it is based on a participatory, collaborative and democratic nature. In general, distributed leadership refers to the ability to include a group of people in various leadership activities. The practice of leadership in a distributed sense results from interactions between the school leader, colleagues and context [14]. This approach describes the leadership practice through the interactions between people and the context, not by defining roles, functions, routines and structures. There is empirical evidence that demonstrates that high performing organizations that follow a distributed structure are characterized by developing a horizontal working structure, frequently create team work and empower their employees making them accountable for their results [15].

The concept of distributed leadership is relatively new and there is not much empirical evidence to demonstrate the actual effects on the students' academic improvement. There are also some key areas of debate, such as the extent to which distributed leadership is necessarily inclusive or democratic; the degree to which it should be taken as a framework for improving leadership practice or simply describing it [16]. This leadership approach offers a new perspective to exercise school leadership and promoting a collaborative work approach.

\section{How the school principal leads a process of academic improvement.}

Initially the research in educational leadership sought to establish direct associations between the school principal management skills with the students' academic performance. However, recent studies are designed to establish a more systemic approach that incorporates the school leader within a context that includes different elements such as leadership style, relationships with teachers, students' demographic and socioeconomic characteristics, and type of school. Within this whole school system, the principal is dedicated to design and implement strategies focused to improve the quality of teaching and the students learning. Viewed this way, the school progress is an effect mediated by the actions promoted by the school leader. The students' academic performance is indirectly impacted by the principal's capacity to promote high quality of teaching, healthy school climate and setting high academic expectations [17].

All schools are different considering the community it is located, students and parents demographic characteristics, teachers believes of education and their interactions between teammates. A relevant role of the school leader is to figure out the school culture considering most of the variables involved on creating it and work with teachers towards shaping a new culture based on common goals that promotes the students high academic expectations. A school principal should use the best strategies toward producing a positive change considering the school context and the specific areas identified for improvement. For example, a principal from a school that consistently shows high academic achievement, in general, shows a higher level of involvement with teachers towards developing curricular planning, visiting classrooms and analyzing evidence that represent the students' learning [4]. All these activities usually are associated with the concept of instructional leadership and involve an active principal that is constantly supporting the implementation the school academic plan and is highly visible for teachers and students. Teachers usually are more motivated to work on a school where the leadership team is centered on developing teaching evaluations that provides constructive feedback centered on developing a positive school climate [18].

However the school leaders should avoid a narrow approach associated with their leadership style finding an appropriate balance between leading towards setting clear expectations on a highly structured organization and promoting professional independence that relies teaching expertize and promote experimentation and innovation. Just centering on implementing an instructional leadership may not be enough to face current challenges on education. Additionally, school principals that are being told to focus on instructional leadership tend to develop an autocratic approach that may obtain short-term results, but in the course of doing this will alienate teachers and will never be able to generate in teachers the motivation and ingenuity for them to be able to go the extra mile [19]. In many occasions, the shift to instructional leadership has led the principalship down an unproductive narrow path of being expected to micromanage or otherwise directly affects instruction. For example, expending huge amount of time observing classrooms will be less effective overall because they cannot influence very many teachers in many given time period; they cannot be experts in all areas of instruction; and they will end up neglecting other aspects of their role that would make a bigger difference, such as developing professional capital of teachers as a group, along with other key aspects of leadership essential for 
motivating people to work together with the leader and others [20].

The leadership behaviors directed to improve the teachers working conditions and their levels of motivation are associated with a transformational leadership style and may produce significant effects of the pedagogical performance of teachers. Therefore it is necessary to consider that the leadership perspective needed to successfully fulfill the current challenges of Chilean schools involves an integrated approach of a variety of school leadership styles. Probably a mixed approach that considers the transformational view of school leadership centered on a redesigning of the organization's culture and believes, together with an instructional leadership focused on improving the quality of instruction at the classroom level may result on a better performance of current schools leaders. Following this idea, Robinson et al [4], recognized the need for developing what they called, shared instructional leadership, where involvement on pedagogical quality and student outcomes employed the combined integrated leadership style.

Recently a concept that involve developing educational leadership considering a variety of perspectives is understood like leadership for learning and considers the students, teachers and the whole school as an organization. So the principal's role is to lead the school's teachers in a process of learning to improve their teaching, while learning alongside them about what works and what doesn't [20]. The proposed research aims to identify and develop the school principals' leadership skills. Since instructional leadership is a well-developed a proven model of leadership for improving the school academic achievement, it is proposed as an initial framework to follow. Afterwards, when the organizational structure is mature enough, more sophisticated leadership approaches (like distributed leadership) may be successfully implemented.

\section{Proposed Research to Address the Problem}

School leadership is recognized as relevant variable that have a potential impact on the students' academic achievement. Which leadership style (instructional, transformational and distributed) responds better to current educational challenges, is still being discussed. This research utilizes the instructional leadership perspective as a cornerstone to begin gathering data about the leadership practices exhibited by Chilean principals. Also, the instructional leadership concept is being used for more than 30 years [8], providing enough systematic data that could be used to evaluate the instructional leadership capacities in Chile.

The Principal Instructional Management Rating Scale (PIMRS, [6]), will be utilized as the conceptual framework to describe the school principal instructional leadership skills. The PIMRS has three broad dimensions of the instructional leadership construct subdivided into ten functions of leadership behaviors: Defining the school's mission, managing the instructional program, and promoting a positive school learning climate. Again, since the PIMRS is a broadly used and validated tool to assess instructional leadership, there is enough empirical data that could be used to compare the finding of this research with situations already described in other countries.

Besides describing the school principals' instructional leadership skills, the information gathered in this research will be helpful to start developing conceptual models to describe mediatedeffects and further reciprocal-effects of school leadership over school improvement. The development of conceptual models based on empirical data will be helpful to identify which variables are associated with the leadership practice can significantly impact the students' performance under the context of Chilean educational system. This is relevant information to plan for staff development and designing policies to strengthen the principals' school leadership capacities.

Building on the premise outlined above, the main research hypothesis states that a developed implementation of instructional leadership by the school principal will be reflected on better student learning. Considering each observed variable that defines the tree dimensions of instructional leadership under the PIRMS scope, the Figure 1 shows the hypothetical Structural Equation Model that will be assessed in the study. Based on this conceptual framework for instructional leadership, it is expected to identify which leadership skills have a higher impact on improving students' outcomes evaluated by a Chilean standardized assessment for reading and mathematics (SIMCE Test).

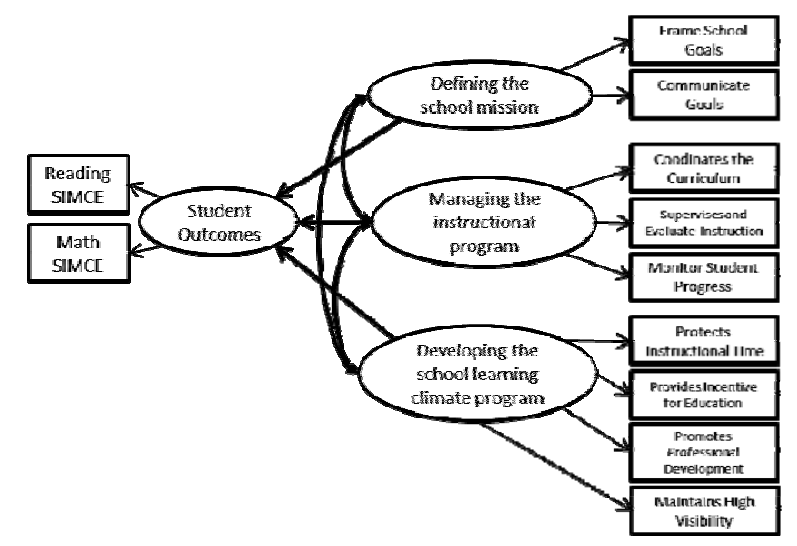

Figure 1. Diagram for hypothetical SEM for instructional leadership effects on students outcome, based on the PIMRS instructional leadership conceptual model. 


\section{Research Questions}

Since measurements on principal's instructional leadership capacities are not extensively being used in Chile, the research questions proposed for the study goes from describing the current state of art, toward developing leadership models based on longitudinal data analysis. Therefore this investigation will be guided by the following questions:

What are the instructional leadership skills of Chilean principals, described by their own perceptions and the school teachers' perception?

There are some generalizing patterns regarding the instructional leadership characteristics observed on Chilean principals? How this is compared with other educational systems?

There are differences between the instructional leadership capacities of school principals working at different school systems (private, private subsidized and public)?

There are differences between the instructional leadership capacities of school principals based on their years or experience?

There are differences between the instructional leadership capacities of school principals based their academic formation (bachelor, master, doctorate)?

There is a relationship between the principals' instructional leadership characteristics and the school results on standardized assessments (SIMCE)?

Improving the instructional leadership capacities of school administrators is reflected on the students academic achievement in midterm (year 1, 2 and 3)?

\section{Methods}

The research will gather data using the PIMRS, a tool designed to enable accurate measurement of instructional leadership practice. The instrument has been employed at different school systems, as well as by more than 200 researchers in published studies and doctoral dissertations. The PIMRS is a 50 -item survey where the rater assesses the frequency with which the principal enacts a particular instructional leadership behavior or practice. Each item is rated on a Likert-type scale ranging from (1) almost never to (5) almost always. The survey will be administered to the principal as a self-rater, and the school teachers rating the principals' instructional leadership behavior.

The data will be gathered from elementary public schools from the Bío-Bío region, Chile. In this area there are a total of 1,204 elementary schools with a total population of 110,878 students. This represents $48 \%$ of the total elementary schools student population of the region. On each participating school, the PIMRS survey will be administered to the principal as a self-rater, and teachers rating the principals' instructional leadership behavior. Then a comparative profile contrasting the perceptions of teachers and the principal will be developed. This comparative profile of the principal's instructional leadership provides an opportunity for the principal to review his or her self-perceptions with those of the teaching staff. It is expected to survey at least 50 elementary schools from the Bío-Bío region to develop and appropriate representation of the principals' instructional leadership capacities.

The data gathered from schools principals and teachers answering the PIMRS survey will be analyzed using descriptive statistics and to develop profiles of the instructional leadership capacities considering the three dimensions measured by the instrument form the principals' self-perspective and the school teachers' perceptions. This information will be used to detect the principals' instructional leadership strength and weakness on each school and the whole sample. Each participating school will receive a personalized report containing the aggregated results of the analysis with specific actions that the administrative team might consider to develop instructional leadership at the school.

Using the systematized information from the PIMRS surveys, the next level of analysis will be the association between the instructional leadership capacities (10 categories measured by PIMRS) and the school effectiveness indicators (SIMCE Scores in Reading and Mathematics). Due to the number of independent and dependent variables being considered, multiple regressions will be used to determine the relationship between each instructional leadership variable being evaluated and the school effectiveness.

A third level of data analysis will be developed using Structural Equation Modeling (SEM). The SEM analysis will be used to better understand the connections between the hypothesized latent variables (three dimensions of instructional leadership model and the student outcomes) and the observed variables (10 instructional leadership functions and Reading and Mathematics SIMCE).

Finally, considering the preliminary data analysis, a total of 15 schools will be selected to participate on an instructional leadership capacity building intervention program. The schools selection will consider the principals and teachers PIMRS surveys results and the school effectiveness indicators. Therefore, the selection process will be focused on the connections found between the instructional leadership dimensions and the school effectiveness indicators found on the previous SEM analysis. Schools principals with lower scores on the instructional leadership dimensions more strongly associated with the school effectiveness indicators will be preferred for this research stage. An instructional leadership capacity building coaching program will be planned with each participating school based on its needs for improvement, the 
principal's instructional leadership profile and research based practices. At the end of the academic year, a new survey will be administered to teachers to measure how instructional leadership capacities have progressed during the coaching process.

\section{Conclusion}

This research will gather information about the Chilean School principals' instructional leadership skills. This leadership style has been well defined and documented as an effective way to improve the instruction and the students' academic achievement. The information gathered in this project will have direct and indirect impact over defining leadership skills needed for school improvement. It is expected that participating schools define a culture that promotes high academic expectations by developing the principal's instructional leadership capacities by implementing research based strategies designed to define the School Educational Plan (Proyecto Educativo Institucional, PEI) and effectively implement the School Improvement Plan (Proyecto de Mejoramiento Educativo, PME). The research findings could be used to direct future professional development for school principals, design new policies related with the job expectations for school leaders and set the initial expectation for further development of different approaches of leadership styles including transformational, distributed leadership and leadership for learning

\section{References}

[1] Murillo J. La dirección escolar en Chile: Una visión en el contexto de América Latina. In: Weinstein J, Muñoz G, editors. ¿Que sabemos sobre los directores en Chile? Salesianos Impresores S.A., Santiago, 2012. pp. 19-40.

[2] Zepeda S. Instructional leadership for school improvement. Eye On Education, Larchmont, NY, 2004.

[3] Marzano RJ, Waters T, McNulty BA. School Leadership That Works: From Research to Results. ASCD, 1st ed, Alexandria,VA, 2005.

[4] Robinson V.M.J., Lloyd C. A. and K. J. Rowe, "The Impact of Leadership on Student Outcomes: An Analysis of the Differential Effects of Leadership Types", Educational Administration Quaterly. 2008;44(5), pp 63574.

[5] Hallinger P. A. Data-Driven Approach to Assess and Develop Instructional leadership with the PIMRS. In: Shen J, editor. Tools for Improving Principals' Work. Peter Lang,New York, 2012. pp. 47-69.

[6] Finkel E. "Principal as Instructional Leaders", District Administration. 2012; 48(6), pp. 50-55.
[7] Hallinger P. A. "Review of Three Decades of Doctoral Studies Using the Principal Instructional Management Rating Scale: A Lens on Methodological Progress in Educational Leadership", Educational Administrational Quaterly. 2010; 47(2), pp. 271-306.

[8] Hallinger P. "Leading Educational Change: Reflections on the practice of instructional and transformational leadership", Cambridge Journal of Education. 2003; 33. pp. 329-352.

[9] Precey R and M.J.R. Entrena M.J.R. "Developing the Leaders We Want to Follow: Lessons from an International Leadership Development Programme". Contemporaneous Management Quaterly. 2011; 2, pp.7083.

[10] Caldwell C, Dixon R.D, Floyd L. A., Chaudoin J, Post $\mathrm{J}$ and G. Cheokas. "Transformative Leadership: Achieving Unparalleled Excellence", Journal Business Ethics. 2011 ;109(2). pp. 175-87.

[11] Leithwood K. ¿Cómo liderar nuestras escuelas? Aportes desde la investigación. Salesianos Impresores S.A.,Santiago, 2009.

[12] Spillane J.P. "Distributed Leadership", Education Forum. 2005; 69(2). pp. 143-150.

[13] Harris A. "Distributed leadership: Friend or Foe?", Educational Leadership. 2013; 41(5):545-54.

[14] Bolden R. "Distributed Leadership in Organizations: A Review of Theory and Research", International Journal Management Review. 2011; 13(3):251-69.

[15] Ten Bruggencate G, Luyten H, Scheerens J, Sleegers P. "Modeling the Influence of School Leaders on Student Achievement: How Can School Leaders Make a Difference?", Educational Administration Quaterly. 2012; 48(4):699-732.

[16] Sammons P, Gu Q, Day C, Ko J. "Exploring the impact of school leadership on pupil outcomes", International Journal Education Management. 2011; 25(1):83-101.

[17] Ten Bruggencate G, Luyten H, Scheerens J, Sleegers P. "Modeling the Influence of School Leaders on Student Achievement: How Can School Leaders Make a Difference?", Educational Administration Quaterly. 2012; 48(4):699-732.

[18] Tapia-Gutiérrez, C. P., Becerra-Peña, S., MansillaSepúlveda, J., \& Saavedra-Muñoz, J. (2011). Liderazgo de los directivos docentes en contextos vulnerables. Educación y Educadores. 2011; 14(2), pp 389-409.

[19] Kirtman, L. Leadership and Teams: The missing piece of the education reform puzzle. Pearson Education, Upper Saddle River, NJ, 2013.

[20] Fullan, M. The Principal: Three Keys to Maximizing Impact. Jossey-Bass, San Francisco, CA, 2014. 